\section{ambient SCIENCE \\ Vol. 05(Sp1):122-126 \\ Year 2018}

\title{
The Impact of Continuous Care Model on Main Symptoms of Myocardial Infarction
}

\section{Mohsen Faseleh', Mojtaba Zeinijahromi*, Sakineh Sabzavari ${ }^{2}$}

'Research Center for Noncommunicable Diseases, Jahrom University of Medical Sciences, Jahrom, Iran

${ }^{2}$ Department of Nursing Kerman University of Medical Sciences, Kerman, Iran

Study Area:Tehran, Iran

Coordinates: $28^{\circ} 30^{\prime}{ }^{\prime \prime} \mathrm{N} ; 53^{\circ} 33^{\prime} 38^{\prime \prime} \mathrm{E}$

Key words: Heart attack, Follow-up Care Model

Received permission from the Ethics Committee of Tehran University of Medical Sciences (911196028-114946) \& the necessary referrals from the relevant hospitals.

\section{Abstract}

Cardiovascular diseases will be the first cause of death and disability by the year $\mathbf{2 0 2 0}$. And, one of the most important diseases in this group is coronary artery disease, which causes a heart attack. Research has shown that controlling the risk factors and the main symptoms of myocardial infarction, can reduce the incidence and complications of many diseases. Therefore, it is become necessary to continuously monitor a care model to reduce the underlying symptoms of heart attacks. We did a randomized clinical trial, on a total of 70 patients with a history of MI who were admitted to study were randomly divided into two groups; test and control. Demographic data and the main symptoms of myocardial infarction questionnaire were completed for both groups. For the test group, a follow-up care model was conducted over a period of 3 months that included four stages of familiarization, sensitization, follow-up, and evaluation. The mean scores for the main symptoms of myocardial infarction in the test group after 3 months were statistically higher than the control group.

occupation and income level etc. (Bolvardi et al., 2014; Beck et al., 2004). Myocardial infarction, in addition to high mortality and multiple complications, imposes a high cost on maintaining the health in countries. For example, in the United States, direct and indirect costs of cardiovascular disease in 2008 were estimated at $\$ 4,753$ billion, whereas in Iran, an annual subsidy of 15 billion Rials is spent on treatment and 50 million dollars is spent on the purchase of medical equipment for their treatment (Khalili et al., 2011; Roger et al., 2012). After a heart attack, patients must be considered themselves as patients and change the behaviors accordingly so that the relevant symptoms, their complications and the risk of recurrence of stroke decrease and leads to the reduction in the frequency of hospitalization and burden of additional costs for the individual and the community. Today, due to the technological advancement, the role of hospitality in treating illness has declined, and patients with complicated diets are often discharged much earlier than the required time periods. Relieving a patient to the home after treatment of a cardiac event is a stressful event for him as the patient does not get the proper opportunity to acquaint his illness while staying in the hospital. Therefore, at home, proper education and follow-up must 
be a good solution for patients suffering from chronic disorders such as heart attacks. On the other hand, the patient has passed the acute phase of the crisis and could better grasp the teaching materials, and remain in close contact with the health care providers, including the nurses in regards to their problems (Artinian et al., 2010; Greenland et al., 2010; Folsom et al., 2009). The follow-up care model is one of the possible ways to cover up the same. This kind of care is a regular and continual process for effective, interactive, and consistent communication between the patient as a needy and a nurse as a provider of health-care services which must be designed to identify the needs, problems and sensitize patients to accept and conduct continuous behaviors. Health care and help maintain their recovery and promote their health (Ghavami et al., 2006).

The main functions of the follow-up care model include recognizing the disease its nature, identifying actual and critical problems related to the disease, accepting the disease and its effects as a shadow in the way of life, playing the role of self-control for good health behaviors, investing in health and well-being Value to health, conflict and family participation in managing current and future issues, changing lifestyle patterns and promoting self-esteem, recognizing the care and treatment team and their use (Nilsaz et al., 2012). Earlier researches of Akbari et al. (2015), Sáei et al. (2012), Ghavami et al. (2006), Sadeghi et al. (2010), Khaneh et al. (2009) and Ahmadi et al., (2009) indicated a positive effect of the follow-up care model on the eff icacy of patients with Cardiac infarction in controlling complications associated with the disease like increasing dialysis adequacy in hemodialysis patients, controlling blood pressure and sleep quality in hemodialysis patients, quality of life in schizophrenic patients, glucose and glycosylated hemoglobin in diabetic patients, and hospitalization and chest pain in patients referred to the hospital. Therefore, it seems that the use of the model has been effective in influencing the main symptoms of myocardial infarction in patients with myocardial infarction and can influence the main symptoms of the disease in reducing the mortality of a large group of people who are today at the age of $35-65$ and at the holding the responsibility in the family and community, also play an important role in cardiovascular disease, especially myocardial infarction (Davati et al., 2006, Wiener et al., 2012) Nevertheless, the effectiveness of this model while providing effective care and promoting community health has once again been tested. Thus, the current research aims to identify the effect of a continuous care model on the main symptoms of aheartattack in the affected patients .

\section{Methodology:}

This report is part of an interventional study of pre and posts clinical trial, performed on 70 patients suffering from myocardial infarction admitted in the two sections of the two hospitals during the three months. The subjects were randomly divided into two groups of 35 individuals each. Our study considered an age limit of fewer than 70 years old, could access the phone properly, and the ability to communicate properly with the researcher, and if the patient experienced a second heart attack, needed a heart surgery, or he expressed his reluctance to cooperate with the researcher in such condition they were kept out of the study. Data collection tool was:i) demographics records for patients who were originally competed for both the groups; ii) the checklist of the main symptoms of the disease, which was developed by researchers using authoritative sources, including reports of dyspnoea, chest pain, fatigue, and the heartbeat. Questionnaires were completed on the daily basis by patients themselves during the time span of 12 weeks. The validity of this questionnaire was verif ied by ten members of the faculty of Kerman University of Medical Sciences. In order to carry out the research and data gathering, one of the researchers daily went to the special cardiac sections and, following the conditions of entry into the study, selected patients. The research project was conducted after receiving written consent from the subjects. The researcher explained the objectives and expressed the necessary explanations in plain language and, gathered the demographic information from the patients. A checklist of main symptoms of the disease, including chest pain, shortness of breath, fatigue, and palpitations were filled up by the patients for both groups of control and testing, and they were asked to label each of such symptoms over the next 12 weeks, and on the other hand the Possibility of communication and appointment and phone contact with the patient at home were also noted. In step (ii) for the control group, the then ongoing trends were treatment and care, and for the test group, the follow-up care model was then going on. Thus, the first step in the follow-up care model, referred as "acquaintance", completed in the approximate time of 3045 minutes, which included communication with the patient, create interest for the participation in the research, motivate the need for continued care and the type of care expected, the correct knowledge of the problem and the request was that there should be continuity and even the lack of interruption of the care relationship.

In the second phase, the sensitization aimed for sensitizing the patient to take responsibility, during sessions between 45 and 60 minutes. The training included the lessons on how to use proper diet, physical activity, the importance of using the dietary regimen, the main symptoms of the disease and the complications of myocardial infarction, and the need to eliminate some of the inappropriate habits, like smoking, and ultimately the need for continued care and the importance of correcting 
the main symptoms of myocardial infarction and modifying the risk factors for the patient and one of his family members. The sum of the first and second phases of the first three weeks was considered as the start-up of the project. The third step in the follow-up care model is the control phase, which lasted for the last 9 weeks of the study, with follow-up consultations on a daily, weekly basis, tailored to the needs of patients in the test group by telephone or attending patients' homes, and checklists. Also, one of the researchers responded to the relevant questions by examining the problems of patients during the four sessions in a group of ten patients from the test group belonging to each session lasted for approximately 90 minutes. The final evaluation was the final stage of the model, aimed to evaluate the care and monitoring of patients' behavior. At this stage, completing the checklist for follow-up forms of follow-up care, the main symptoms of the disease, and the feedback regarding the success or failure of the actions were carried out with the help of the patient and their family members were considered for appropriate solutions. Further recommendations are provided whereever felt necessary. During the course of the study, the patients were contacted each week with a telephone call to remind for fill up the checklist for the main symptoms of the disease. After completing the follow-up care model, all checklist for the main symptoms of the disease were collected from both the control and control groups. Then, they were analyzed using SPSS softwareversion 19 .

\section{Results:}

The findings showed that $75 \%$ of the subjects were in the age group of $30-60$ years old and $54.3 \%$ were men. The level of literacy in most of them was under the diploma (40\%). In terms of marital status and type of occupation, the majority of the subjects were single $(65.7 \%)$ and $34.28 \%$ were properly employed, and, according to the records of the underlying causes of heart disease, $78.6 \%$ were from hypertension, $57 \%$ reported themselves as diabetics and $32.9 \%$ were smokers.

The following table compares the incidence of the various symptoms of the disease. The mean of frequencies of the main symptoms of the disease (shortness of breath, chest pain, palpitations, and fatigue) in the intervention group 3 during the follow up month was signif icantly lower than that of the group before the intervention. The incidence of these symptoms over the course of three months in the control group, although didn't decrease.

The results of our study showed that out of the total 200 respondents, $44.5 \%$ are the most spiritual intelligence, $18.5 \%$ had the least spiritual intelligence, and the rest $37 \%$ did not respond in this regard. Further, $12 \%$ had the highest self-eff icacy and 10\% had the lowest self-efficacy and the rest had a moderate overall self-eff icacy (Table-2).
Table-1: Frequency distribution of demographic information including diabetic status, blood pressure and history of smoking.

\begin{tabular}{|c|c|c|c|c|}
\hline Paramater & Number & $\%$ & Number & $\%$ \\
\hline \multicolumn{5}{|c|}{ Agegroups (p>0.49) } \\
\hline $30-40$ & 10 & $14 \cdot 3$ & o & 14.1 \\
\hline $41-50$ & 10 & $14 \cdot 3$ & 10 & 14.1 \\
\hline $51-60$ & 10 & $14 \cdot 3$ & 10 & 14.1 \\
\hline $61-70$ & 3 & $4 \cdot 3$ & 3 & 4.2 \\
\hline $71-75$ & 2 & 2.9 & 2 & 2.8 \\
\hline \multicolumn{5}{|l|}{ Gender (p>0.62) } \\
\hline Man & 19 & $54 \cdot 3$ & 19 & 5433 \\
\hline Female & 16 & $45 \cdot 7$ & 16 & $45 \cdot 7$ \\
\hline \multicolumn{5}{|c|}{ Education level $(p>0.20)$} \\
\hline Under the diploma & 16 & $45 \cdot 7$ & 12 & $34 \cdot 3$ \\
\hline Diploma & 7 & 20 & 11 & 31.4 \\
\hline Bachelor & 9 & $25 \cdot 7$ & 8 & 22.9 \\
\hline Master's degree & 3 & 8.6 & 4 & 11.4 \\
\hline \multicolumn{5}{|c|}{ Marital Status ( $>>0.69)$} \\
\hline Single & 24 & 68.8 & 22 & 62.9 \\
\hline Married & 6 & 17.1 & 8 & 22.9 \\
\hline Widow & 3 & 6.8 & 4 & 11.4 \\
\hline divorced & 2 & $5 \cdot 7$ & 2 & 2.9 \\
\hline \multicolumn{5}{|c|}{ Occupation/job profile (p>o.6o) } \\
\hline Free & 12 & $34 \cdot 3$ & 9 & $25 \cdot 7$ \\
\hline Employee & 12 & $34 \cdot 3$ & 12 & $34 \cdot 3$ \\
\hline Retired & 4 & 11.4 & 6 & 17.1 \\
\hline housewife & 7 & 20 & 8 & 22.9 \\
\hline \multicolumn{5}{|c|}{ Blood pressure $(p>0.43)$} \\
\hline YES & 26 & 74.2 & 29 & 82.9 \\
\hline $\mathrm{NO}$ & 9 & $25 \cdot 7$ & 6 & 17.1 \\
\hline \multicolumn{5}{|c|}{ Diabetic status $(p>0.1)$} \\
\hline YES & 21 & 60 & 19 & $54 \cdot 3$ \\
\hline $\mathrm{NO}$ & 14 & 40 & 16 & $45 \cdot 7$ \\
\hline \multicolumn{5}{|c|}{ Smoking habit ( $\mathrm{p}>0.49)$} \\
\hline YES & 11 & 31.4 & 12 & $34 \cdot 4$ \\
\hline $\mathrm{NO}$ & 24 & 68.6 & 23 & 65.7 \\
\hline
\end{tabular}

Table-2: Comparative chart of the average occurrence of the main symptoms of the disease during the 3 months follow up

\begin{tabular}{llllllllll}
\hline $\begin{array}{l}\text { Para- } \\
\text { meters }\end{array}$ & \multicolumn{3}{l}{$\begin{array}{l}\text { Control (during study) } \\
\text { Beginning }\end{array}$} & \multicolumn{4}{l}{$\begin{array}{l}\text { End } \\
\text { Mean SD }\end{array}$} & Mean SD & \multicolumn{2}{l}{$\begin{array}{l}\text { Before After } \\
\text { Mean }\end{array}$} & SD & Mean & SD \\
\hline Chest P & 16.40 & 2.09 & 19.30 & 2.28 & 16.40 & 2.09 & 6.30 & 1.42 \\
Heart B & 16.10 & 2.07 & 18.20 & 2.21 & 16.10 & 2.074 & 4.50 & 1.30 \\
Breath S & 15.54 & 2.03 & 17.52 & 2.16 & 15.50 & 2.03 & 7.10 & 1.47 \\
Fatigue & 19.3 & 2.28 & 21.2 & 2.41 & 19.2 & 2.28 & 5.66 & 1.37 \\
\hline
\end{tabular}

Chest P- Chest pain; Heart B-Heart beat; Breath S-Shortness of breath. Statistically each parameter difer from other at $\mathrm{p}<0.0001$.

The table above shows the incidence of the main symptoms related to the disease. The mean of frequencies of the main symptoms of the disease (shortness of breath, chest pain, palpitations and fatigue) in the intervention group during 3 the follow-up month was significantly lower than that of the group before the intervention. The frequency of these symptoms increased during the three 
months, although it did not decrease in the control group.

\section{Discussion:}

The comparison of the mean scores of various parameters regarding the main symptoms of myocardial infarction in the studied groups before intervention was indicative of the consistency of these two groups and the comparison of the mean scores of the different parameters of the main symptoms of myocardial infarction in the subsequent study groups. The intervention in the test group has significantly increased while compared with the control group, which is consistent with the results of the study by Norlund et al. (2018); Gulliksson et al., (2011); Smith \& Blumenthal (2011) reported that the behavioral and physical counseling after few months improved the patient's physical and behavioral behavior and after a year of quality of life improved the quality of patients. Also, in a study of Baghaei et al. (2015) the implementation of this model evidenced the improvement in the quality of life of patients in the test group in all aspects of the physical, emotional and general, and the test group which differed statistically from the control group. Ahmadi et al. (2005) also indicated that using a follow-up care model on the indicators such as the number of hospitalization, the frequency of visits to the physician, the level of blood lipids, diet modification, the frequency of use sublingual nitroglycerine tablets improves the quality of life of effective coronary patients. Zaidi et al. (2005) reported that the patients gradually forget their care recommendations after get discharged from the hospital, so gets necessary to strengthen the information and, on the other hand, to identify inappropriate health behaviours of the patients regarding myocardial infarction in the absence of follow-up. In a cross-sectional study that aimed to determine self-care behaviors in patients with myocardial infarction within 15 and 30 days after getting discharged from the hospital Niakan et al. (2013) showed that on the fifteenth day of discharge, in the majority of patients $(72 \%)$ self-care behaviour were felt desirable while on the thirtieth day most of them (84.1\%) showed undesirable self-care behaviours and there was a significant difference between these behaviours between the 15th and 3oth day after discharged. The results of the present study are consistent with the results of the study by Davoodvand et al. (2009) which was aimed to establish the effect of short-term cardiac rehabilitation programs on the course of clinical manifestations of myocardial infarction in patients with myocardial infarction. The results of this study showed that participation in rehab programs reduced attacks include increased blood pressure and shortness of breath, fatigue, palpitations, and chest pain.

Conclusively, today, around the world, the healthcare community is on the way of improving the quality of services for patients to have a greater impact on the health of the community. One of the examples and ways to improve the quality of services for patients is to continuously monitor their health and treatment issues until they reach its maximum level. If such issues would be handled by the trained nurses who constitute the largest professional group in the health care system this reduces the cost of treatment and the frequency of hospitalization. It could only be achieved, by a follow-up care model for all the patients, and especially for patients with myocardial infarction.

\section{Acknowledgment:}

This article is a part of the thesis of Nursing Masters in Internal Medicine and Mojtaba Zeini Jahromi medical surgical from Kerman University of Medical Sciences. Researchers are grateful towards the Kerman University of Medical Sciences for the credibility of this research as well as the staff \& partners of the special departments of Motahhari Hospitals \& Peymaniyeh Jahrom for their honesty \& loyalty while carrying out this study.

\section{References:}

Ahmadi, F. (2002): Design and evaluation of a continuous care model in the management of patients with chronic coronary artery disease. PhD Thesis submitted to. Tehran, Iran: Tarbiat Modares University. [Persian].

Ahmadi, F., Ghofranipour. F., Abedi. H.A., Abedi. H.A. \& Faghihizadeh, S. (2005): Effect of continuous consultation care model on rehospitalization and chest pain in patients with coronary artery disease. J. Qazvin Uni. Med. Sci., 9(2): 99103. [Persian].

Akbari, O., Vagharseyyedin, S.A., Saadatjoo, S.A. \& Kazemi, T. (2015): Effect of Continuous Care Model on the Self-Efficacy of Patients with Myocardial Infarction in Controlling Disease Complications. Med.Surg. Nur. J., 3(4):194-185.

Artinian, N.T., Fletcher, G.F., Mozaffarian, D., Kris-Etherton, P., Van Horn, L., Lichtenstein, A.H., Kumanyika, S., Kraus, W.E., Fleg, J.L., Redeker, N.S., Meininger, J.C., Banks, J., Stuart-Shor, E.M., Fletcher, B.J., Miller, T.D., Hughes, S., Braun, L.T., Kopin, L.A., Berra, K., Hayman, L.L., Ewing, L.J., Ades, P.A., Durstine, J.L., Houston-Miller, N. \& Burke L.E. (2010): Interventions to promote physical activity and dietary lifestyle changes for cardiovascular risk factor reduction in adults: a scientific statement from the American Heart Association.Circulation, 122(4):406-441.

Azizi, F., Emami, H.,Salehi, P., Ghanbarian, A., Mirmiran, P. \& Mirbolooki, M.R. (2003): Cardiovascular risk factors in the elderly: Tehran Lipid and Glucose Study (TLGS). Iran. J. Endocrinol. Metabol., 5(1):3-13.

Baghaei, R., Mashallahi, A., \& Khalkhali, H. (2015): The Effect of applying continuous care model on quality of life in heart failure patients. JUrmia Nurs Midwifery Fac.,13 (8):666-675.

Beck R.J., Pollak, A.N. \& Rahm, S.J. (2004): Intermediate Emergency Care and Transportation of the Sick and Injured. Pub. by: Jones \& Bartlett Learning. 1596 p.

Bolvardi, E., Reihani, H., Pishbin, E., Sanei, A. \& Ebrahimi, M. (2014): Comparison of educational effectiveness between lecture and demonstration based methods on emergency medical services providers of Mashhad city in dealing with patients suspected of having acute coronary syndrome. Med. J. Mashhad Uni. Med. Sci., 57(5):711-718. 
Davoodvand, Sh., Elahi, N. \& Haghighizadeh, M. (2009): Effectiveness of Short-term Cardiac Rehabilitation on Clinical Manifestations in Post-MI Patients. J. Fac. Nurs. Midwif. Tehran Uni. Med.Sci., (Hayat), 15(3):72-81.

Davati, A., Alikhah, A., Safabakhsh, M., Gharebaghi, R., Razzaghi, M.H., Mehri, M. \& Khajouie, P. (2006): Effects of education on students' parents' knowledge. Med. Sci. J. Islamic Azad Uni., 16(1):35-38.

Folsom, A.R., Yamagishi, K., Hozawa, A. \& Chambless, L.E. (2009): Absolute and Attributable Risks of Heart Failure Incidence in Relation to Optimal Risk Factors. Circ Heart Fail., 2(1):11-17.

Ganguli, D., Das, N., Saha, I., Sanapala, K.R., Chaudhuri, D., Ghosh, S. \& dey, S. (2011): Association between Inflammatory Markers and Cardiovascular Risk Factors in Women from Kolkata, W.B, India. Arq Bras Cardiol., 96 (1):38-46.

Ghavami, H., Ahmadi, F., Entezami, H. \& Meamarian, R. (2006): The Effect of Continuous Care Model on Diabetic Patients' Blood Pressure. Iran. J. Med.Edu., 6 (2):87-95.

Greenland, P., Alpert, J.S., Beller, G.A., Benjamin, E.J., Budoff, M.J., Fayad, Z.A., Foster, E., Hlatky, M.A., Hodgson, J.M., Kushner, F.G., Lauer, M.S., Shaw, L.J., Smith, S.C., Taylor, A.J., Weintraub, W.S. \& Wenger, N.K. (2010): ACCF/AHA Guideline for Assessment of Cardiovascular Risk in Asymptomatic Adults: Executive Summary A Report of the American College of Cardiology Foundation/American Heart Association Task Force on Practice Guidelines. Circulation, 122:2748-2764.

Gulliksson, M., Burell, G., Vessby, B., Lundin, L., Toss, H. \& Svärdsudd, K. (2011): Randomized controlled trial of cognitive behavioral therapy vs standard treatment to prevent recurrent cardiovascular events in patients with coronary heart disease: Secondary Prevention in Uppsala Primary Health Care project (SUPRIM). Arch Intern Med.,171(2):134-140.

Khaneh, H.R., Anjomanian, V., Ahmadi F, Falahi, K.M., Rahagozar, M. \& Ranjbar, M. (2009). evaluating the effectiveness of continuous care model on quality of life in discharged Schizophrenic patients from Sina Educational and Medical Center Hamedan, 2007. Iran. J. Nurs. Res., 4(15):70-6o.

Khalili, A., Yaghoubi, A., Safaie, N., Eyvazi, K., Azarfarin, R., Ebrahimzadeh, A., Alizadehasl, A., Safarzadeh, G., Farzandan, A. \& Zamanzadeh, A. (2011): Incidence of Cardiovascular Risk Factors in Oskoo (Northwest Iran): An Approach through WHO CVD-risk Management Package for Low-and Medium-Resource Settings on 37,329 Adults $=30$ Years Old. L. Cardiovasc. Thorac. Res., 3(4):103-108.

Koenig, W. (2013): High-sensitivity C-reactive protein and atherosclerotic disease: from improved risk prediction to risk-guided therapy. Int. J. Cardiol.,168(6):5126-5134.
Niakan, M., Paryad, E., Shekholeslam, F., Leili, E.K., Rad, M.A., Bonakdar, H.R., Bouraki, S. (2013). Self Care Behaviors in Patients after Myocardial Infarction. J. Holistic Nurs. Midwifery, 23(2):63-70.

Nilsaz, M., Tavassoli, E., Mazaheri, M., Sohrabi, F., Khezeli, M., Ghazanfari, Z. \& Mirzaei, A. (2012): Study of Healthpromotion behaviors and Life Style among students of Dezful universities. J. Ilam Uni. Med. Sci., 20(4):1-5.

Norlund, F., Wallin, E., Olsson, E.M.G., Wallert, J., Burell, G., von Essen, L. \& Held, C. (2018): Internet-Based Cognitive Behavioral Therapy for Symptoms of Depression and Anxiety Among Patients With a Recent Myocardial Infarction: The UCARE Heart Randomized Controlled Trial. L. Med. Internet Res., 20(3): e88.

Roger, V.L., Go,A.S., Lloyd-Jones, D.M., Benjamin, E.J., Berry, J.D., Borden, W.B., Bravata, D.M., Dai, S., Ford, E.S., Fox, C.S., Fullerton, H.J., Gillespie, C., Hailpern, S.M., Heit, J.A., Howard, V.J., Kissela, B.M., Kittner, S.J., Lackland, D.T., Lichtman, J.H., Lisabeth, L.D., Makuc, D.M., Marcus, G.M., Marelli, A., Matchar, D.B., Moy, C.S., Mozaffarian, D., Mussolino, M.E., Nichol, G., Paynter, N.P., Soliman, E.Z., Sorlie, P.D., Sotoodehnia, N., Turan, T.N., Virani, S.S., Wong, N.D., Woo, D. \& Turner, M.B. (2012): Heart disease and stroke statistics--2012 update: a report from the American Heart Association. Circulation,125(1):e2-e220.

Sadeghi Sherman, M., Razmjuee, N., Ebadi, A., Najafi Mehri, S., Asadi-Lari, M. \& Bozorgzad, P. (2009): Effect of applying continuous care model on quality of life of patients after coronary artery bypass graft. Iran. J. Crit. Care Nurs., 2:1-6.

Sadeghi, H.A., Forouzi, A.M., Haghdust, A.A., Alizadeh, M.S. (2010): Effect of implementing continuous care model on sleep quality of hemodialysis patients. Iran. J. Crit. Care Nursi., 3(1):12-18. [Persian].

Saei, A., Mazhari, M., Tayybi, A. \& Ebadi, A. (2012): The effect of continuous care model on dialysis adequacy in hemodialysis patients of selected Iranian army hospitals. Police Medicine, 1(2):105-112.

Smith, P.J. \& Blumenthal, J.A. (2011): Psychiatric and Behavioral Aspects of Cardiovascular Disease: Epidemiology, Mechanisms, and Treatment. Rev Esp Cardiol., 64(10):924933.

Wiener, C., Kasper, D.L., Fauci, A.S., Hauser, S.L., Longo, D.L., Jameson, J.L., Loscalzo, J., Brown, C. \& Houstan, B. (2012): Harrisons principles of internal medicine selfassessment and board review. 18th ed, Pub. by: McGraw Hill, New York.

Zaidi, I., Heidarnia, A. \& Hajizadeh, E.. (2005): Study of lifestyle in cardiovascular patients. Daneshvar: Esfand, 13(6):49-56. (Persian)

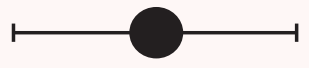

